\title{
Lugares de interés geomorfológico, geopatrimonio y gestión de espacios naturales protegidos: el Parque Natural de Valderejo (Álava, España) ${ }^{1}$
}

\author{
María José González Amuchastegui², Enrique Serrano Cañadas ${ }^{3}$ \\ y María González García ${ }^{4}$
}

\begin{abstract}
RESUMEN
Este trabajo destaca la necesidad de incorporar el análisis de los elementos geomorfológicos a la gestión de los espacios naturales protegidos. Dentro de ellos, los lugares de interés geomorfológico o geomorfositios, se erigen en auténticos recursos de valor patrimonial, ya que a su valor natural unen otra serie de valores culturales y de uso, constituyendo útiles de desarrollo local. El objetivo del trabajo es inventariar, definir y valorar los geomorfositios del Parque Natural de Valderejo (Álava, España) aplicando una metodología semicuantitativa basada en la combinación de sus valores intrínsecos, añadidos y de uso; todo ello ha permitido definir en Valderejo cinco geomorfositios sobre los que se plantean distintas propuestas de gestión basadas en sus respectivas valoraciones. La metodología empleada se ha mostrado útil como medio para inventariar, diagnosticar y definir propuestas encaminadas a una mejor gestión de los geomorfositios del Parque, siendo aplicable a otros espacios naturales protegidos.
\end{abstract}

Palabras clave: Lugares de interés geomorfológico, geopatrimonio, evaluación, espacios naturales protegidos.

\begin{abstract}
This paper attempts to highlight the need to incorporate geomorphological elements into the management of protected natural areas, as a major element in the articulation of the natural system. The geomorphological heritage is constituted of sites of interest called Geomorphosites that included scientific but also added, cultural or scenic values, which make them authentic heritage resources. For assessment of geomorphosites, a semi-quantitative methodology based on the intrinsic added value and use was been applied. The study focuses on inventorying and evaluating geomorphosites in Parque Natural de Valderejo (Álava, Spain). Five geomorphosites have been inventoried and evaluated in Valderejo; for each site an assessment was conducted proposals are for management and use are provided for a few sites. The methodology has proved useful as a means to inventory, diagnose and define proposals for better management of the geomorfosites in Parque Natural de Valderejo, and could be applicable for other protected natural areas.
\end{abstract}

Key words: Geomorphosites, Heritage, Assessment, Valderejo, Protected Natural Areas.

\footnotetext{
1 Este trabajo se enmarca en el proyecto UNESCO09/05 (Cátedra Unesco de Desarrollo Sostenible) y los Grupos de Investigación Consolidado Tipo A IT622-13 (Dpto. Geografía, Prehistoria y Arqueología, UPV/EHU) y GIR Patrimonio Natural y Geografía Aplicada (PANGEA) (Dpto. Geografía, UVA). Artículo recibido el 6 de diciembre de 2013, aceptado el 20 de agosto de 2014 y corregido el 30 de septiembre de 2014
}

2 Departamento de Geografía, Universidad del País Vasco (España). E-mail: mj.gonzaleza@ehu.es

3 Departamento de Geografía, Universidad de Valladolid (España). E-mail: serranoe@fyl.uva.es

4 Departamento de Geografía, Universidad de Málaga (España). E-mail: maria_gonzalez@hotmail.com 
El relieve es uno de los elementos principales en la configuración de los espacios naturales protegidos, ya que dirige la distribución del resto de los factores ambientales y territoriales: clima, vegetación y usos de suelo; de hecho el marco geomorfológico proporciona la base de su organización territorial y en muchos casos en él se sustenta gran parte del atractivo de dichos espacios e incluso los argumentos que justificaron su declaración. Y es que los elementos abióticos, además de sostén o infraestructura del paisaje, en muchas ocasiones llegan a conformar su aspecto más significativo, pudiéndose hablar expresamente de paisajes geomorfológicos.

Sin embargo, hasta tiempos recientes la consideración de los aspectos abióticos y del relieve en particular, ha sido relegada a un segundo plano en la mayor parte de los estudios así como en las propuestas de planificación. Actualmente son numerosos los países tanto en Europa como en América en los que dichos aspectos van siendo integrados en los estudios territoriales empleando para ello términos relativamente nuevos como son los de geodiversidad o lugares de interés geomorfológico (Panizza, 2001; Gray, 2004; Reynard, 2005; Serrano \& González Trueba, 2005; Serrano \& Ruiz Flaño, 2007, 2009).

El patrimonio geomorfológico constituye parte del patrimonio natural con una fuerte adscripción territorial y paisajística. Este valor patrimonial del relieve procede de su carácter heredado, su significado paleoambiental, de la escasez de estas formas en el ámbito territorial en el que se inscribe y como condicionante para los usos y emplazamientos humanos; todos estos aspectos unidos al contexto social en el que la sociedad demanda este tipo de paisajes de fuerte componente geomorfológica, los convierte en recursos territoriales de potencial impacto socioeconómico.

El trabajo se inscribe en esta línea, con especial atención al geopatrimonio y la geodiversidad como elementos de conocimento de la naturaleza útiles para su gestión y conservación (Gray, 2004); este planteamiento es conforme con el "Manifiesto Europeo para el Patrimonio Terrestre y la Geodiversidad" (2004) realizado por la Unión Geográfica Internacional (IGU), la European Geoparks
Network, European Society for Soil Conservation y la Unión Internacional de Ciencias Geológicas (IUGS), y se inscribe dentro de la temática desarrollada por el Working Group on Geomorphosites de la Asociación Internacional de Geomorfólogos (IAG) pero con una consideración escalar y territorial, y su aplicación a Espacios Naturales Protegidos, concretamente al Parque Natural de Valderejo situado en la provincia de Álava (España). Tras una introducción en la que se definen los lugares de interés geomorfológico y la metodología de valoración, se presenta el territorio de Valderejo, Parque Natural en el que sus aspectos geomorfológicos tienen protagonismo tanto en su configuración espacial como en su dinámica territorial; se aplica la metodología indicada y se exponen los resultados: definición de cinco lugares de interés geomorfológico (LIGm), se presenta su valoración y diferentes propuestas de gestión para finalizar con una discusión de los resultados y de la metodología empleada.

\section{Los lugares de interés geomorfológico}

En este trabajo nos centramos en el inventario y valoración de los lugares de interés geomorfológico (LIGm), también denominados geomorfositios, formas y asociaciones de formas de relieve de especial interés monumental, escénico, ecológico, pedagógico o científico, que son esenciales en la configuración morfológica y en la dinámica y evolución de los espacios naturales protegidos (ENP) (Panizza \& Piacente, 1993, 2003; Reynard, 2005). Los LIGm presentan un valor científico para la reconstrucción de la historia humana y de la Tierra, así como para la comprensión de la organización del territorio, el paisaje y el patrimonio natural. Además, poseen otros valores adicionales, culturales, científicos y socioeconómicos que incrementan su valor, convirtiéndolos en recursos patrimoniales cuya gestión debe ser abordada desde la sostenibilidad al ser necesario garantizar su pervivencia para generaciones futuras.

Por otro lado, los lugares de interés geomorfológico se erigen en muchos ENPs como sus principales factores de atracción, lo que les convierte en auténticos recursos de utili- 
dad turística, educativa (Serrano \& González Trueba, 2011) y ambiental, que permite obtener un máximo rendimiento social a su valoración. La potencialidad de estos recursos no se circunscribe exclusivamente al ámbito turístico, sino también al científico, didáctico y paisajístico, en tanto que deben ser analizados desde el compromiso con la conservación y el uso pedagógico y social. Por ello, es necesario incorporar al planeamiento territorial figuras como los LIGm, herramientas útiles para diagnosticar y valorar los aspectos geomorfológicos, no solo para dar a conocer, evaluar y potenciar su uso, sino también para definir criterios de protección especial cuando sea necesario, teniendo en cuenta el uso turístico, pedagógico o ambiental y asegurando la sostenibilidad del recurso.

Los geomorfositios constituyen útiles y adecuados instrumentos de gestión territorial en los espacios naturales protegidos que van siendo incorporados paulatinamente como recursos a escalas regionales, locales o de los espacios protegidos (Panizza \& Piacente, 2003; Reynard, 2005). Su estudio es complejo puesto que al análisis objetivo de los rasgos geomorfológicos hay que añadirle una valoración de carácter más subjetivo que integre los valores culturales, paisajísticos, pedagógicos y turísticos. En su análisis se incluye por tanto, el estudio de elementos objetivos, reales, en definitiva formas de relieve, y una valoración de carácter más subjetiva que depende de las complejas relaciones que se establecen entre la sociedad y el medio. Para abordar su estudio, Reynard (2009) propone un modelo conceptual que diferencia el relieve y el paisaje geomorfológico. El relieve estaría compuesto por valores tangibles, las distintas formas de relieve (Regolini, 2011), generadas por procesos geomorfológicos endógenos, exógenos y antrópicos que son la parte geomorfológica objetiva del paisaje. Por otro lado, el paisaje geomorfológico sería la parte del relieve visto, percibido y a veces utilizado por el hombre.

La diferencia entre relieve y paisaje geomorfológico se relaciona con la presencia de filtros de percepción, vinculados a factores sociales e individuales y son los que se encuentran en la base de la valoración. Estos valores son de índole científica, ecológica, cultural, estética y económica. Este marco es adecuado y trasladable al análisis de los geomorfositios ya que puede establecerse una analogía entre el paisaje geomorfológico y los geomorfositios, siempre teniendo en cuenta las diferencias de tamaño y complejidad que los separan (Reynard, 2009). Dentro de los distintos valores que se otorgan a los paisajes geomorfológicos en general como en los geomorfositios en particular, la dimensión estética es muy importante aunque no debe ser la única.

De esta idea se deduce la dificultad que surge a la hora de atribuir valores científicos y adicionales a los geomorfositios puesto que se trata de recoger los valores atribuidos por diferentes actores (científicos, autoridades públicas, asociaciones, usuarios, etcétera). A excepción del valor intrínseco, atribuido por los científicos, el reconocimiento de la mayor parte de los valores adicionales deriva de los lazos existentes entre los geomorfositios y la sociedad; pueden ser de orden cultural, socioeconómico o estético, dependiendo de los sistemas de valores de las personas o las sociedades, y son susceptibles de variar a lo largo del tiempo (dinámicos), son por tanto intangibles, no son directamente visibles. (Cendrero, 1996; Regolini, 2012).

Finalmente, los LIGm constituyen, tal y como se ha dicho, elementos de alto valor intrínseco para el establecimiento de la historia de la Tierra pero también para la reconstrucción de la evolución de los paisajes y la configuración de los territorios. Los geomorfositios incluyen frente a otros geositios o lugares de interés geológico (paleontológicos, estructurales, mineralógicos), un componente estético, primordial en su dimensión como recurso turístico, tienen un carácter dinámico que permite analizar los procesos actuales y su evolución, lo cual les otorga un gran valor didáctico y en ellos se produce una imbricación de escalas (Reynard, 2005) puesto que Ilevan implícita una dimensión espacial (paisajística y territorial), cuya escala puede variar, aunque su impronta es generalmente grande, es decir son territorial y paisajísticamente significativos.

La dimensión patrimonial de las geoformas y la posibilidad de pérdidas irreversibles conduce a reflexionar sobre la necesidad de conocer y valorar el patrimonio geomorfo- 
lógico en un marco territorial y paisajístico concreto, el Parque Natural de Valderejo sobre el que se establece una definición y evaluación de los geomorfositios mediante la adaptación a este contexto territorial de metodologías ya aplicadas.

Metodología de valoración de los lugares de interés geomorfológico (L/Gm)

Para abordar la realización del inventario y valoración de los lugares de interés geomorfológico del Parque Natural de Valderejo se ha seguido una metodología que contempla la complejidad señalada en el estudio de los geomorfositios y que ya ha sido empleada y validada por el equipo en otros espacios de alta montaña y rurales del norte de España (Serrano \& González Trueba, 2005; Serrano et al., 2009; González Trueba y Serrano, 2008; Pellitero et al., 2010), del centro de la Península Ibérica o en Canarias (Dóniz-Páez et al., 2011, 2013). Se han aplicado modificaciones respecto a las anteriores metodologías centradas fundamentalmente en la propuesta de valoración de uso y gestión, con el objetivo de dar a los LIGms un carácter más aplicado y de fácil utilización por los gestores del Parque Natural. Con ello se busca rentabilizar al máximo la dimensión de herramienta de gestión que tiene el geomorfositio en toda su potencialidad, científica, didáctica o turística, planteando propuestas de uso encaminadas a garantizar la pervivencia del recurso geomorfológico. Además, el carácter aplicado que se persigue con esta metodología se plasma en la elaboración de una cartografía orientada a facilitar su uso por los gestores del Parque Natural. En este sentido es importante reseñar que se persigue ofrecer un instrumento práctico y fácilmente utilizable por los gestores pero también comprensible por el público en general.

La metodología (Figura $N^{\circ} 1$ ) parte del conocimiento geomorfológico profundo del territorio, que se plasma en la elaboración de una cartografía geomorfológica a escala 1:25.000, herramienta básica en el inventario y localización de las formas y procesos

Figura $\mathrm{N}^{\circ} 1$

Síntesis metodológica para la evaluación de los lugares de interés geomorfológico

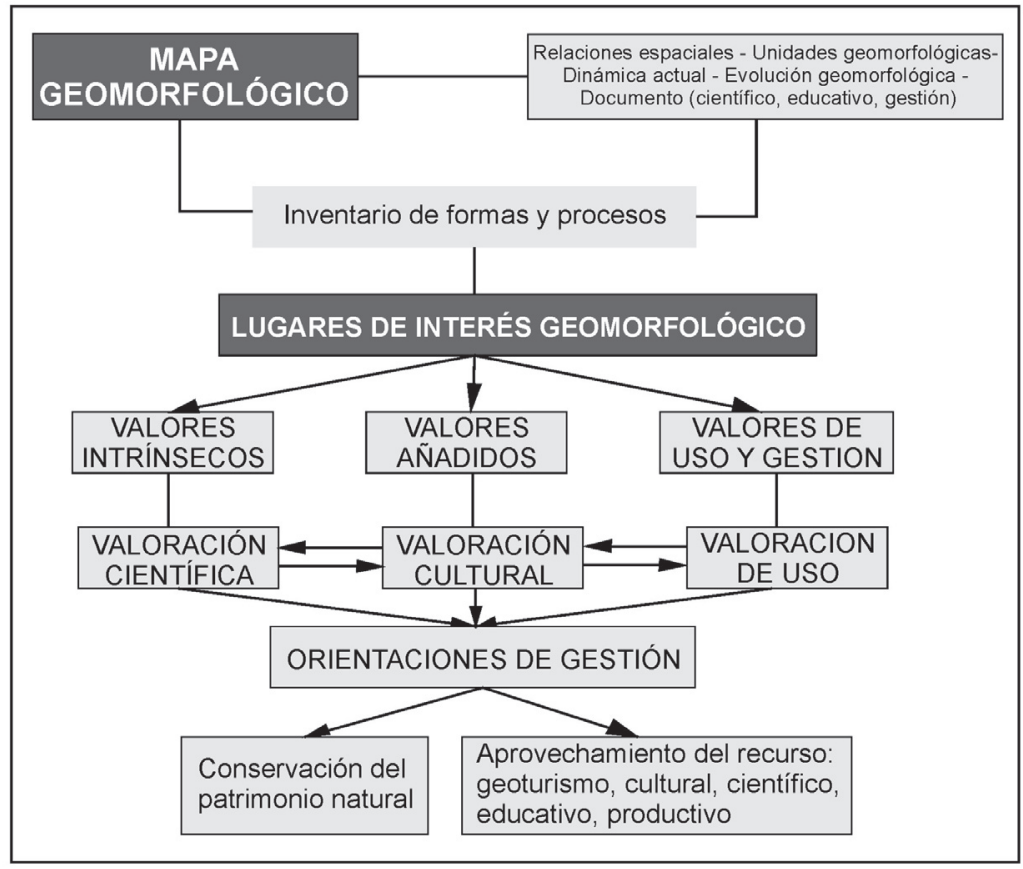

Fuente: Elaboración propia. 
y sus relaciones espaciales. A partir de esta cartografía, se seleccionan los elementos geomorfológicos, se clasifican en lugares o elementos y en singulares o representativos, y se procede a la definición del listado de lugares de interés geomorfológico. La tercera fase es la valoración de cada uno de ellos, su diagnóstico y una propuesta de uso y gestión. Para ello se elabora una ficha descriptiva de cada geomorfositio, que incluye sus aspectos más representativos, y se aplica una triple valoración por separado de:

- Valores científicos (o intrínsecos), puramente geomorfológicos y que incluye una valoración referida a los valores estructurales, morfológicos, dinámicos y de diversidad (Cuadro $\mathrm{N}^{\circ} 1$ ).

Cuadro $\mathrm{N}^{\circ} 1$

Evaluación de los valores intrínsecos

\begin{tabular}{|c|c|c|c|}
\hline Identificación & Nombre: & Lugar: & $\mathrm{N}^{\mathrm{o}}$ : \\
\hline \multirow{2}{*}{ Situación } & \multicolumn{3}{|c|}{ Término municipal: } \\
\hline & Coordenadas: & Altitud: & \\
\hline $\begin{array}{l}\text { Tipo de } \\
\text { Geomorfositio }\end{array}$ & \multicolumn{2}{|c|}{$\begin{array}{l}\text { LUGAR REPRESENTATIVO: Hace referencia en su carácter repre- } \\
\text { sentativo (condición ejemplar o modelo) de la geomorfología de la } \\
\text { zona. }\end{array}$} & Valoración \\
\hline \multirow{7}{*}{$\begin{array}{l}\text { Valores } \\
\text { intrínsecos }\end{array}$} & \multirow{2}{*}{ Morfoestructura } & $\begin{array}{l}\text { Litología (número, significación, representativi- } \\
\text { dad, rareza) }\end{array}$ & Máximo 5 \\
\hline & & $\begin{array}{l}\text { Tectónica ( número, significación, representativi- } \\
\text { dad, rareza) }\end{array}$ & Máximo 5 \\
\hline & \multicolumn{2}{|c|}{$\begin{array}{l}\text { Diversidad de otros elementos de interés geológico (se consideran } \\
\text { otros elementos geológicos: tectónicos, estratigráficos, paleontológi- } \\
\text { cos, mineralógicos, petrológicos, hidrogeológicos ) }\end{array}$} & Máximo 5 \\
\hline & \multirow{2}{*}{ Morfología } & $\begin{array}{l}\text { Formas de erosión: número, significación, repre- } \\
\text { sentatividad, rareza }\end{array}$ & Máximo 10 \\
\hline & & $\begin{array}{l}\text { Formas de acumulación: número significación, } \\
\text { representatividad, rareza }\end{array}$ & Máximo 10 \\
\hline & \multirow{2}{*}{ Dinámica } & $\begin{array}{l}\text { Heredados: significación, representatividad, rare- } \\
\text { za: (1-5) }\end{array}$ & Máximo 5 \\
\hline & & $\begin{array}{l}\text { Funcionales: significación, representatividad, ra- } \\
\text { reza: }(1-5)\end{array}$ & Máximo 5 \\
\hline
\end{tabular}

Fuente: Elaboración propia.

- Valores añadidos, que suman valores a los elementos anteriores; entre ellos se incluyen los valores paisajísticos, estéticos, culturales, didácticos, científicos y turísticos (Cuadro $\mathrm{N}^{\circ} 2$ ).

- Valores de uso y gestión: Se refieren a la capacidad de uso que presenta el LIGm, teniendo en cuenta sus potencialidades pero también aspectos como la fragilidad y el riesgo de degradación. En definitiva, en este tercer bloque, se trata de valorar la potencialidad de cada geomorfositio como componente patrimonial y recurso, tratando de considerar ambos valores y gestionando su compatibilidad. Debido al carácter aplicado de la propuesta y para una mejor comprensión por parte de los gestores del Parque Natural, se ha optado por subdividir la valoración de uso y gestión en dos apartados, fragilidad y poten- 
Cuadro $\mathrm{N}^{\circ} 2$

Evaluación de los valores añadidos

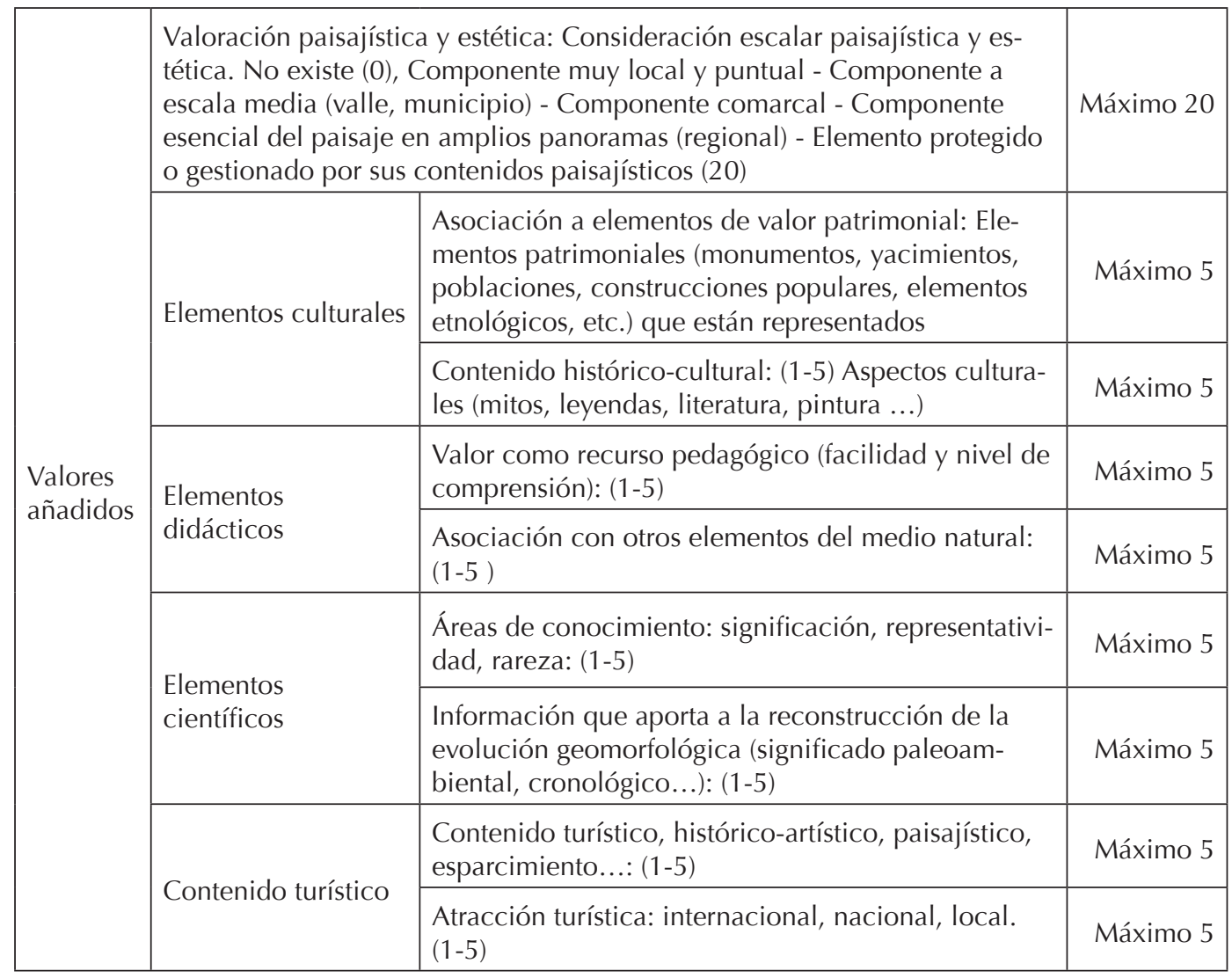

Fuente: Elaboración propia

cialidad de uso. Esta modificación persigue convertir a los LIGm en una herramienta práctica y no supone ningún problema añadido a la hora de establecer comparativas con LIGm de otros ENPs, puesto que lo que se compara es el resultado obtenido y no el proceso metodológico. Finalmente se incluye un apartado referido a la orientación del uso y gestión del LIGm así como un conjunto de propuestas de actuación sobre él (Cuadro $N^{\circ} 3$ ).

El resultado final, de carácter semicuantitativo (utiliza una escala de 1 a 5), permite establecer comparaciones entre el conjunto de los geomorfositios, y a su vez conocer qué valores (intrínsecos, añadidos o de uso y gestión) son los más destacados en el contexto del propio geomorfositio. Para ello se ha establecido una escala en la que se considera un valor bajo, cuando este es inferior a 1,5, medio cuando se encuentra entre 1,5 y $3, y$ alto para los valores superiores a 3 .

Toda la información aparece recogida en una ficha en la que además se incluye información cartográfica de localización, contextualización estructural, un mapa geomorfológico de detalle y un bloque interpretativo de carácter geomorfológico-didáctico (Figuras, No 6 y 7 ).

Por otro lado, la propuesta incluye la confección de otros productos gráficos, como son mapas de localización que contienen información sobre la valoración y que tienen la virtualidad de su expresividad y utilidad para el técnico o gestor, confección de tablas con grupos de LIGm según su carácter dominan- 


\section{Cuadro $\mathrm{N}^{\circ} 3$}

Evaluación de los valores de uso y gestión

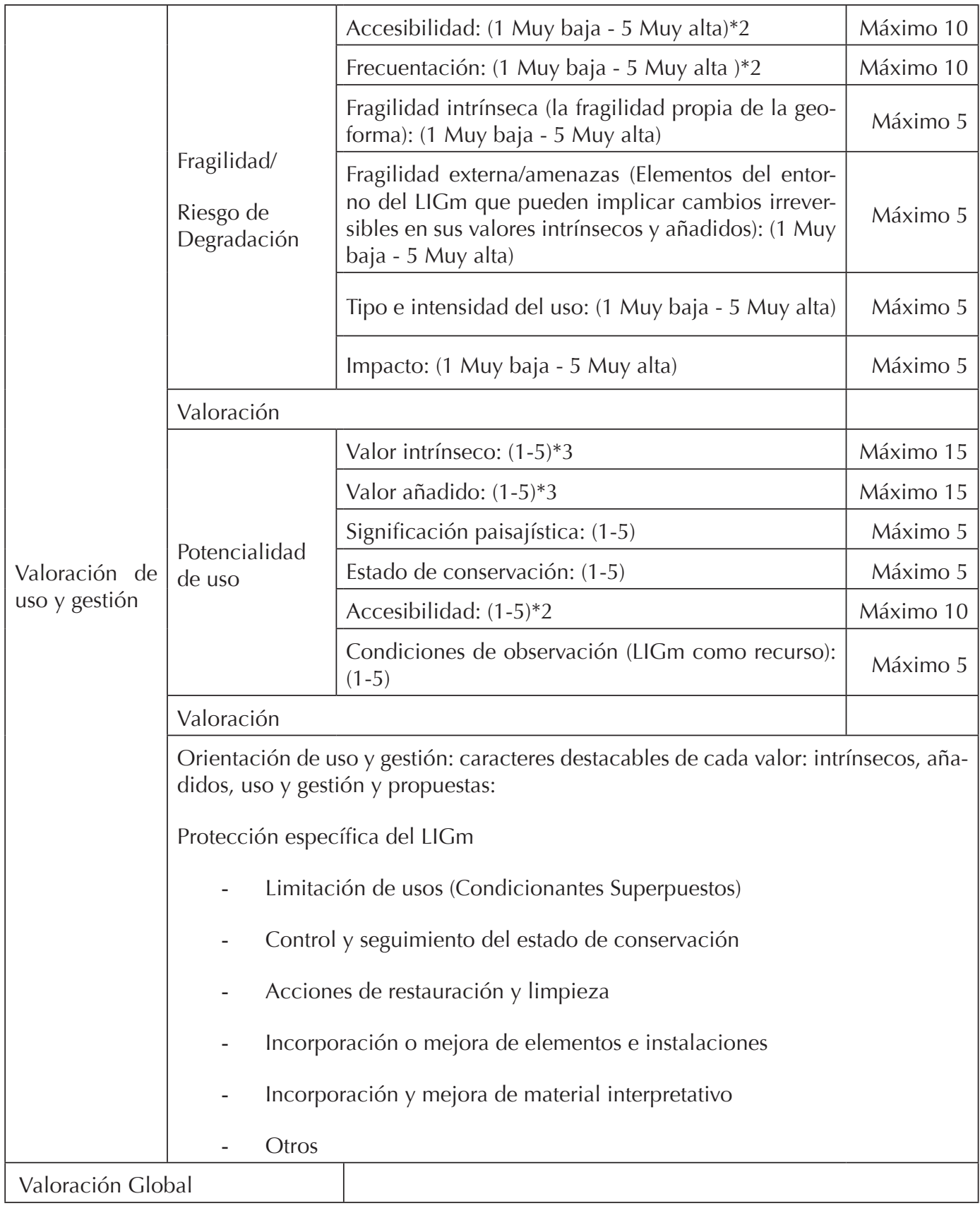

Fuente: Elaboración propia.

te (intrínseco, añadidos, uso y gestión), así como características más relevantes detectadas en ellos. Se trata de una información útil para el gestor, pero también para la posterior interpretación de los LIGm por guías, monitores, profesores o usuarios. 
Figura $\mathrm{N}^{\circ} 2$

Localización de la zona de estudio

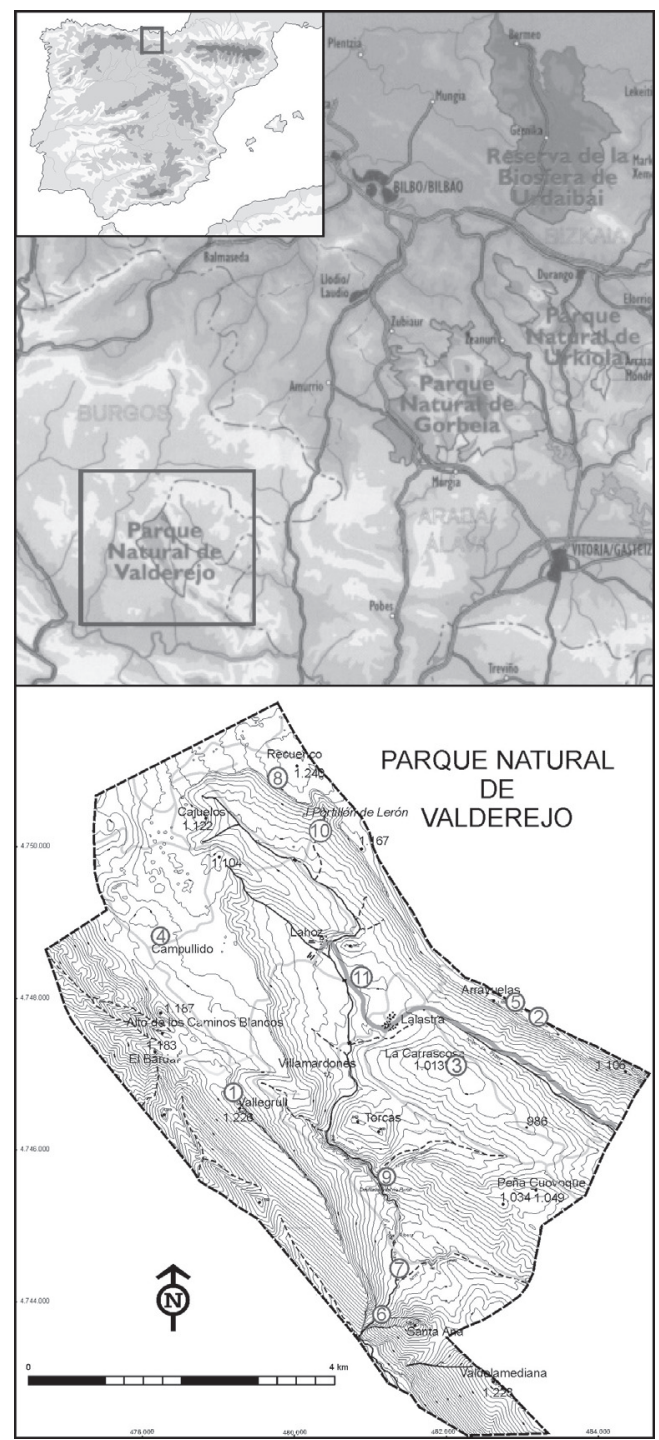

Fuente: Elaboración propia.

\section{Valderejo, un Parque Natural de fuerte protagonismo geomorfológico}

El Parque Natural de Valderejo se sitúa en el extremo occidental de Álava (Figura No 2), en una zona en la que esta provincia forma un apéndice que penetra en tierras de Burgos. Valderejo fue declarado Parque Natural en
1992 y presenta una superficie de 3.418,5 ha, con una elevada altitud media próxima a los 1.000 m. (977 m.). El entorno inmediato también disfruta de un grado de protección importante al presentar continuidad territorial por el sur en el Parque Natural de Montes Obarenes-San Zadornil, declarado en 2006.

\section{El marco geomorfológico}

Valderejo se sitúa en la vertiente meridional de la cordillera Cantábrica, concretamente en las montañas de Burgos, espacio dominado por los relieves plegados, de amplios sinclinales de gran radio -sinclinal de Villarcayo, sinclinal de Valdivielso, Ranera-y apretados anticlinales generados por una tectónica eyectiva, que da como resultado un relieve conforme en el que los sinclinales constituyen relieves negativos concordantes y los anticlinales conforman relieves positivos.

Concretamente, Valderejo forma parte del gran eje anticlinal de Lahoz y queda enmarcado por las sierras de Bóveda y Arcena que constituyen los flancos de una gran estructura anticlinal desventrada, que viene a coincidir con los límites del Parque; de hecho existe una gran coincidencia entre la superficie abarcada por el Parque Natural y el entramado estructural. Dominan los materiales cretácicos de naturaleza carbonatada en los que alternan las calizas y dolomías con los niveles margosos; el núcleo del anticlinal está formado por las arenas del Albiense, que constituyen un sector deprimido dada la mayor deleznabilidad de los materiales. El flanco norte del anticlinal presenta buzamientos más marcados e incluso subverticales que el flanco S, y su núcleo está fallado por un sistema de fracturas de dirección E-W. Presenta una morfología elíptica como consecuencia del cierre NW periclinal, constituyendo la combe de Arcena. Esta constituye en sí misma un elemento geomorfológico que articula el paisaje y la organización interna del territorio, erigiéndose en elemento singular de alto valor pedagógico y científico.

En este contexto estructural, la red fluvial ha sido el principal agente morfogenético (González Amuchastegui, 1993; González Amuchastegui y Serrano, 1996), con formas fluviales que responden a una larga evolución ambiental con alternancia de fases de acumu- 


\section{Panorámicas del Parque Natural de Valderejo}
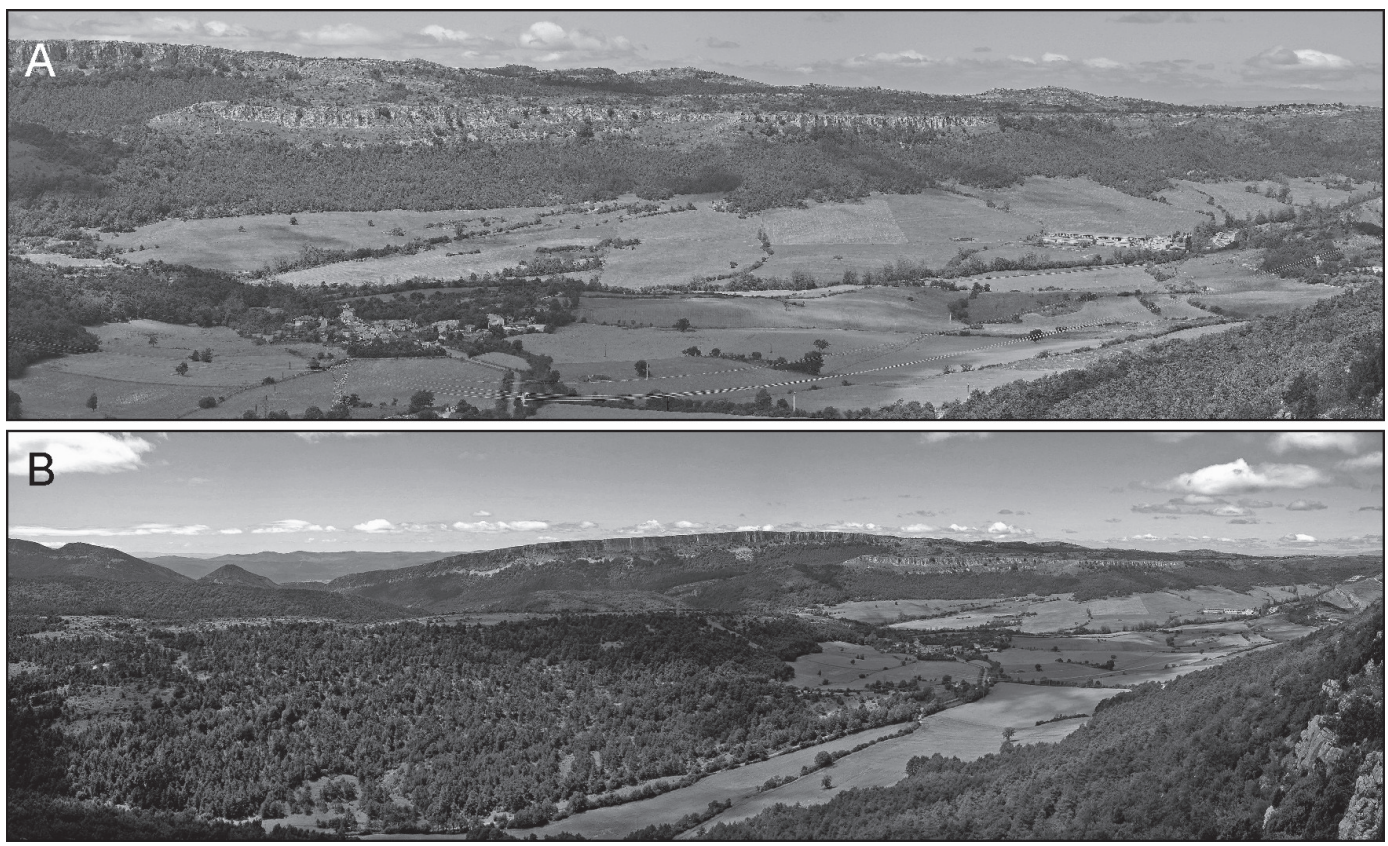

Fuente: Elaboración propia.

lación y erosión. El río Purón, tributario del río Ebro, nace en la sierra de Arcena y recorre el parque, incidiendo en las margas turonienses del núcleo del anticlinal para atravesar su flanco meridional con un trazado zigzagueante adaptado a la sucesión de materiales. La morfología del valle se adapta a la estructura, alternando los tramos de valle amplios y las gargantas, debido a la sucesión de pasillos margosos ortoclinales y barras calizas monoclinales que definen la estructura del flanco.

El predominio de los materiales calcáreos en los flancos y en el cierre perianticlinal determina la importancia del karst. A pesar de ello, las formas exokársticas no son muy numerosas y se sitúan principalmente en la bóveda del cierre periclinal o de los flancos del anticlinal, representadas por campos de dolinas y lapiaces de la zona del Recuenco, Vallegrull y Arrayuelas. Por el contrario, el endokarst presenta un desarrollo más acentuado aunque todavía no ha sido estudiado en profundidad.
La dinámica kárstica se traduce en la presencia de un importante relleno tobáceo que en el fondo de valle del Purón supera los $20 \mathrm{~m}$ de potencia. Las estrechas gargantas del valle presentan pequeñas rupturas de pendiente que sirven de base para la génesis de edificios tobáceos de barrera. Estos se resuelven mediante grandes cascadas tobáceas hoy desconectadas de la circulación actual del río. Aguas arriba de estas barreras tobáceas vinculadas a la retención de las aguas se produjo un importante relleno calcarenítico consecuencia de la destrucción de edificios tobáceos situados más arriba. En el valle del Purón (Figura $N^{\circ} 3$ ) se ha detectado una única generación de construcciones tobáceas de edad holocena (González Amuchastegui \& Serrano, 2005 y 2007), apoyadas en algunos de los tramos del valle sobre depósitos estratificados asociados al último episodio de frío intenso del Pleistoceno reciente. Actualmente estos edificios han sufrido una fuerte incisión, aunque en el valle se constatan procesos activos de precipitación tobácea. 
Figura $\mathrm{N}^{\circ} 4$

Imágenes del valle del río Purón. A. Incisión fluvial en el dorso monoclinal del valle del Purón. B. Valle abierto y cascadas con edificios tobáceos. C. Pequeño resalte tobáceo
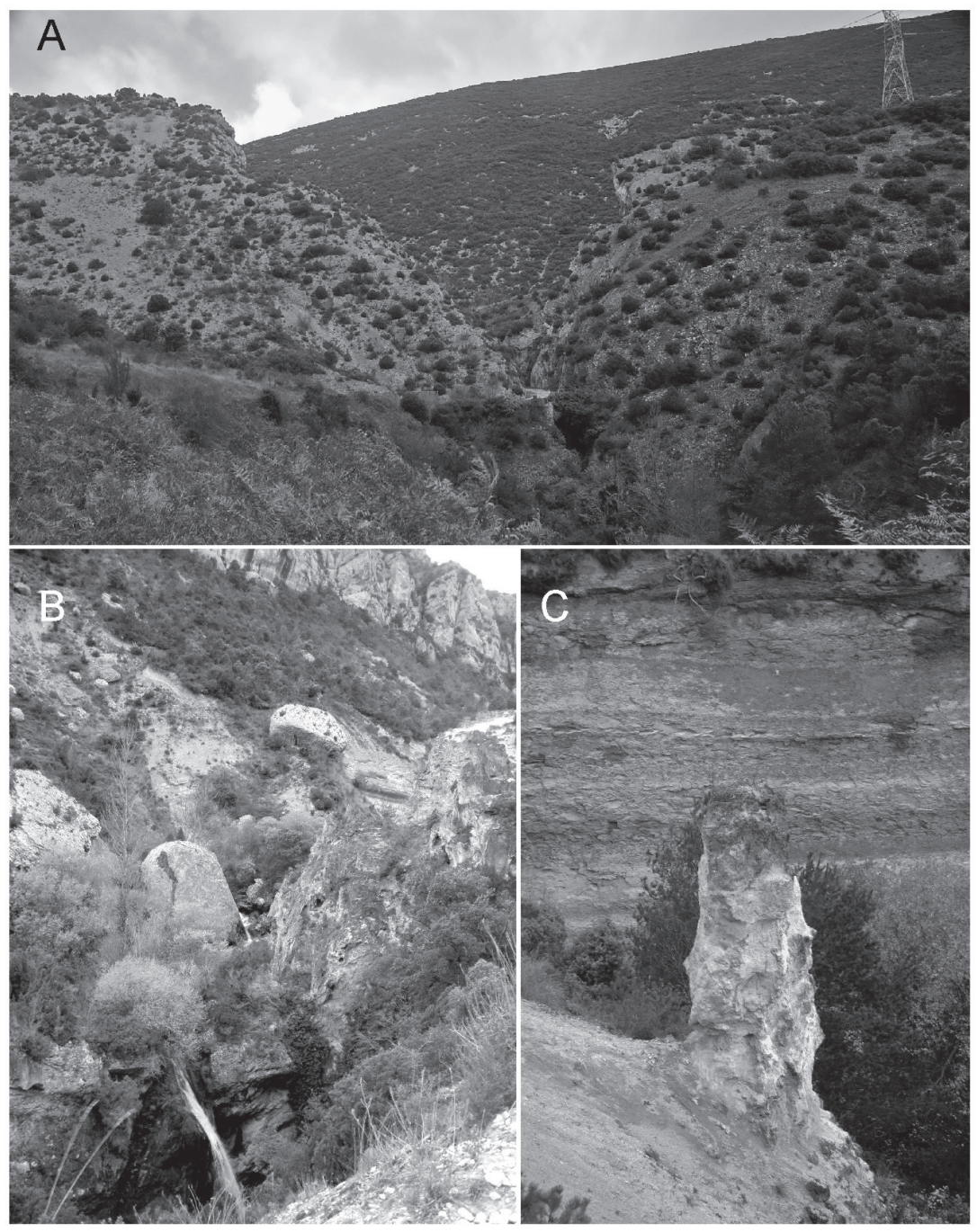

Fuente: Elaboración propia.

El territorio actual: un paisaje de intensa imbricación cultural y natural

La posición periférica de Valderejo respecto a los grandes ejes de desarrollo socioecononómico, en un apéndice occidental de la provincia de Álava que ha sufrido graves problemas de despoblación, explica en gran medida el buen estado de conservación paisajístico del Parque y ese hecho a su vez se encuentra en estrecha dependencia de sus condicionantes geomorfológicos y topográficos. El parque cuenta con cuatro núcleos de población, dos habitados, Lalastra y Lahoz, con menos de una docena de habitantes entre ambos en el 2011, y dos deshabitados, Villamardones y Ribera.

Los cambios socioeconómicos de la década de 1960, desembocaron en agudos desequilibrios interterritoriales, de manera que sociedades agrícolas que hasta el momento 
habían mantenido cierta estabilidad social y demográfica, se adentraron en un proceso de desvertebración socioeconómica que desarticuló el modelo tradicional de explotación agraria y gestión territorial, y condujo al desmantelamiento de la infraestructura social y emigración de gran parte de sus habitantes (Garayo, 1977). En este contexto el territorio de Valderejo, desarticulado socioeconómicamente pero caracterizado por un medio natural y paisajes tradicionales bien conservados, pasó a ser objeto de demanda con alto valor para una sociedad urbanizada que reclamaba nuevos espacios de ocio. De manera que tras un proceso que arranca en los años 80, Valderejo fue declarado Parque Natural (1992) convirtiéndose en el tercer espacio protegido de la Comunidad Autónoma del País Vasco y el primero de Álava, y uno de los que cuenta con mayor patrimonio natural a pesar de su reducida extensión.
Pero además, Valderejo cuenta con un importante patrimonio cultural, relacionado con el río Purón, paso natural entre el valle del Ebro y la costa cantábrica, utilizado desde el Paleolítico medio hasta la actualidad, con reconocidos elementos arquitectónicos, etnográficos e históricos. Este paso natural constituye una vía de comunicación y de organización del hábitat del valle al que se asocian manifestaciones culturales que engloban desde arte rupestre, prehistórico y cristiano, lo que parece indicar que fue una de las vías de acceso de la cristiandad en Álava (Aldama y Galilea, 2006), hasta numerosos túmulos, campos tumulares y menhires. Aunque de manera desigual, están bien representados el Paleolítico Medio hasta las edades del Bronce, Edad del Hierro, la romanización y las sociedades medievales (Cuadro $N^{\circ} 4$ ). Todo ello le ha valido de base para la propuesta de declaración de Valderejo como Parque Arqueológico (III PGRUG, 2011).

Cuadro $\mathrm{N}^{\circ} 4$

Inventario de elementos arqueológicos de interés

\begin{tabular}{|l|r|l|}
\hline Elementos de interés arqueológico & $\begin{array}{c}\text { Número de } \\
\text { manifestaciones }\end{array}$ & \multicolumn{1}{|c|}{ Edad } \\
\hline Talleres y canteras de silex & 2 & Paleolítico medio \\
Túmulos y campos tumulares & 15 & Holoceno \\
Menhires & 3 & Holoceno \\
Dólmenes & 1 & Holoceno \\
Estructuras megalíticas & 1 & Holoceno \\
Yacimientos al aire libre & 7 & Edades del Bronce y del Hierro \\
Pinturas rupestres & 2 & Holoceno \\
Covachos, abrigos y cuevas eremíticas & 8 & Edad del Bronce, medievales \\
Poblados & 4 & Edad del Hierro \\
Cabañas y estructuras pastoriles de la Mesta & 1 & Moderna \\
Obra civil: puentes, caminos y fuentes & 5 & Roma, medieval, Moderno \\
\hline
\end{tabular}

Fuente: Aldama y Galilea, 2006.

En la actualidad, el turismo es un recurso económico importante y Valderejo se mantiene como el Parque Natural que recibe mayor número de visitantes de los ubicados en el País Vasco, 39.941 visitantes en 2011, a pesar de la notable caída del turismo ecológico en los Parques Naturales del País Vasco. En este sentido es importante señalar que algunos de los lugares de interés geomorfológico definidos en Valderejo tienen el potencial para 
convertirse en "lugares de interés turístico" por sí mismos y por tanto deben ser considerados recursos territoriales cuya gestión debe garantizar el equilibrio entre conservación y sostenibilidad (Cuadro $\mathrm{N}^{\circ} 5$ ).

Cuadro $\mathrm{N}^{\circ} 5$

Visitantes del Parque Natural de Valderejo

\begin{tabular}{|c|c|c|c|c|c|}
\hline \multicolumn{2}{|l|}{ Visitantes } & 2008 & 2009 & 2010 & Total \\
\hline \multicolumn{2}{|l|}{ Total } & 60.273 & 60.300 & 40.211 & 120.573 \\
\hline \multirow[t]{2}{*}{ Casa del parque } & $\mathrm{N}^{\circ}$ & 27.862 & 23.992 & 23.049 & 51.854 \\
\hline & $\%$ del total & 46,2 & 39,8 & 57,3 & 43 \\
\hline \multirow[t]{4}{*}{ Grupos } & $\mathrm{N}^{\circ}$ de grupos & 106 & 97 & 81 & 203 \\
\hline & $\mathrm{N}^{\circ} \mathrm{VG}$ & 66 & 62 & 38 & 128 \\
\hline & Participantes en VG & 2.601 & 2.415 & 1.294 & 5.016 \\
\hline & $\%$ Grupos en VG & 63,9 & 46,9 & 63,1 & -- \\
\hline \multirow[t]{2}{*}{ Escolares } & $\mathrm{N}^{\circ}$ de grupos & 42 & 41 & 42 & 83 \\
\hline & $\mathrm{N}^{\circ}$ de personas & 1.739 & 1.654 & 1.828 & 3.393 \\
\hline
\end{tabular}

VG, visitas guiadas. Fuente: Parque Natural de Valderejo.

\section{Los lugares de interés geomorfológico del Parque Natural de Valderejo}

La fuerte componente geomorfológica del Parque Natural de Valderejo constituye uno de sus principales atractivos tanto a una escala grande -como se señaló, la propia delimitación del espacio natural coincide con una geoforma-, como a una escala más limitada que queda definida por los lugares de interés geomorfológico; en efecto el componente geomorfológico se erige en uno de los recursos territoriales más relevantes del parque, implicando la necesidad de realizar un inventario y valoración de los lugares de interés geomorfológicos, en aras de promover una gestión territorial que asegure la sostenibilidad del recurso.

Tras una primera propuesta inicial que incluía un listado de 12 LIGms destacados por sus valores geomorfológicos, un segundo análisis más detallado, tanto de reconocimiento de formas en el campo como la aplicación de la valoración y estudios específicos de cada
LIGm Ilevó a la selección de un listado definitivo de 5 (Cuadro $N^{\circ}$ 6). Estos son altamente representativos de la geomorfología del parque y de sus paisajes, y pueden agruparse en tres grandes grupos:

- LIGm de Vallegrull y Arrayuelas (números 1 y 2): representativos del relieve estructural, ambos conforman los flancos NE y SW de la combe de Arcena, dibujando crestas con intensa karstificación en sus dorsos y una activa dinámica de laderas en el frente (Figura $\mathrm{N}^{\circ} 5$; Figura $\mathrm{N}^{\circ} 6 \mathrm{~A}, \mathrm{~B}, \mathrm{C}$ y J; Figura $\mathrm{N}^{\circ} 7$ ).

- LIGm del Recuenco-Portillo Lerón: constituye el cierre periclinal del pliegue con forma abovedada y presenta asimismo una profusa karstificación y dinámica de laderas, que incluyen formas de gran originalidad como las laderas de bloques situadas a su pie (Figura $\mathrm{N}^{\circ} 6 \mathrm{D}$ e I).

- LIGm del valle del río Purón (3 y 4): constituyen un magnífico exponente del paisaje fluvio-kárstico regional. El río Purón modifica la morfología del valle adaptado a las morfoestructuras, de manera que desarro- 

espacios naturales protegidos: el Parque natural de Valderejo (Álava, ESPAÑA)

Ila una sucesión de amplios pasillos margosos ortoclinales con terrazas tobáceas bien desarrolladas, y gargantas fluviales conformadas en las barras calizas monoclinales (Figura $\mathrm{N}^{\circ}$ $6, F, G, H$ e I). Se ha desarrollado un impor- tante conjunto de cascadas tobáceas que responden a unas condiciones hidrodinámicas específicas por el estrechamiento del cauce que facilitan la construcción de los edificios tobáceos (Figura $N^{\circ} 4$ ).

Figura $\mathrm{N}^{\circ} 5$

Mapa geomorfológico del lugar de interés geomorfológico $n^{\circ} 2$. Arrayuelas

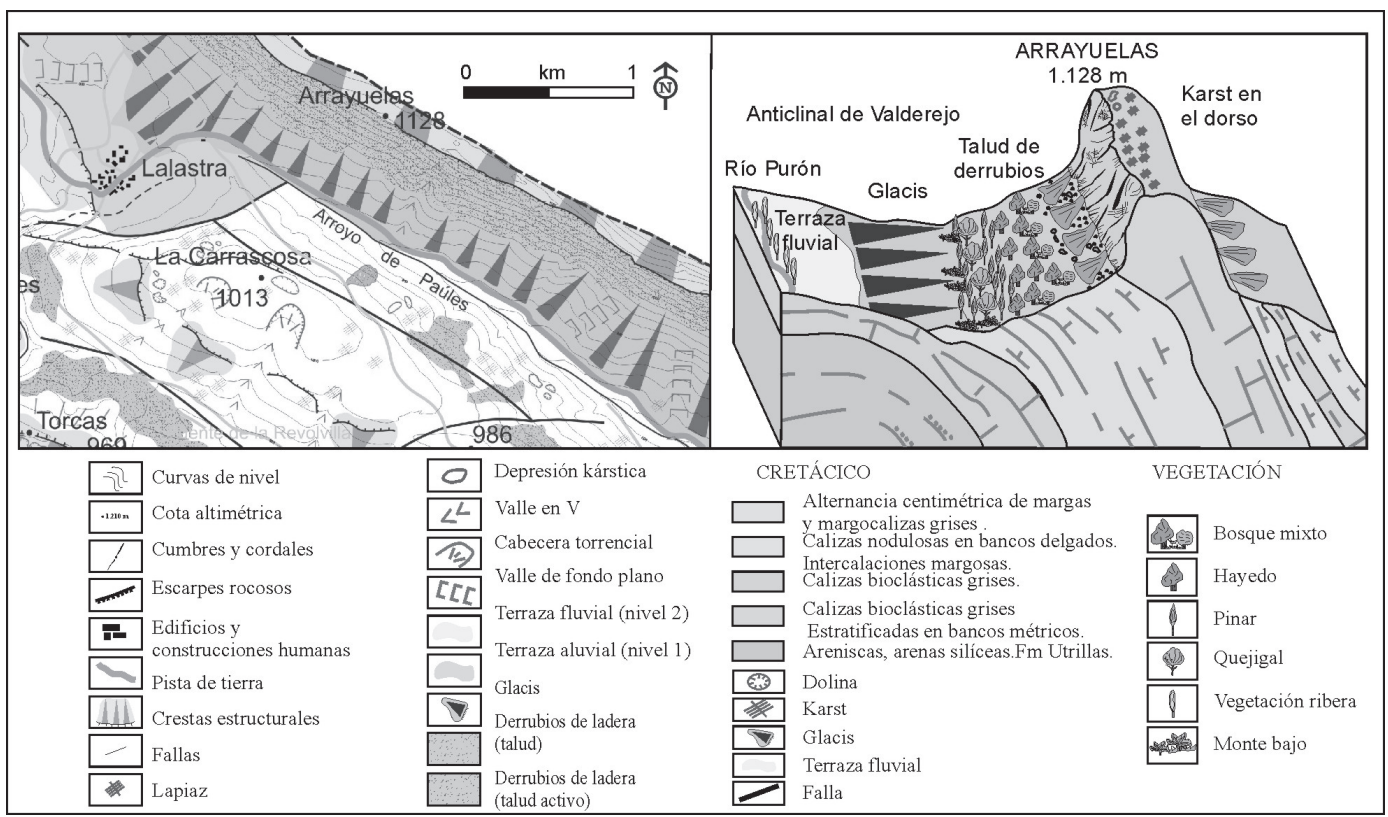

Fuente: Elaboración propia.

Cuadro $\mathrm{N}^{\circ} 6$

Lugares de interés geomorfológico del Parque Natural de Valderejo y valoración

\begin{tabular}{|c|c|c|c|c|c|}
\hline \multirow{2}{*}{$\begin{array}{l}\text { Lugar de Interés } \\
\text { Geomorfológco }\end{array}$} & \multirow[b]{2}{*}{$\mathrm{N}^{\mathrm{o}}$} & \multirow{2}{*}{$\begin{array}{c}\text { Valor } \\
\text { intrínseco }\end{array}$} & \multirow{2}{*}{$\begin{array}{c}\text { Valor } \\
\text { añadido }\end{array}$} & \multicolumn{2}{|c|}{ Valor de Uso y Gestión } \\
\hline & & & & $\begin{array}{c}\text { Fragilidad/ } \\
\text { vulnerabilidad }\end{array}$ & $\begin{array}{l}\text { Potencialidad } \\
\text { de uso }\end{array}$ \\
\hline Vallegrull & 1 & 3,2 & 3,3 & 1,2 & 2,7 \\
\hline Arrayuelas & 2 & 3 & 2,8 & 1,37 & 2,5 \\
\hline Valle Abierto río Purón & 3 & 3,8 & 3,9 & 2,8 & 3,7 \\
\hline Desfiladero río Purón & 4 & 3,7 & 3,9 & 3 & 3,7 \\
\hline Recuenco-Portillón.Lerón & 5 & 3,3 & 3,3 & 1,12 & 2,7 \\
\hline
\end{tabular}

Fuente: Elaboración propia. 
Figura $\mathrm{N}^{\circ} 6$

Lugares de interés geomorfológico del P.N. de Valderejo. A, B, C: Vallegrull. E: Valle abierto del río Purón; F, G y H, Desfiladero río Purón; I, Recuenco-Portillo Lerón. J y D: Arrayuelas

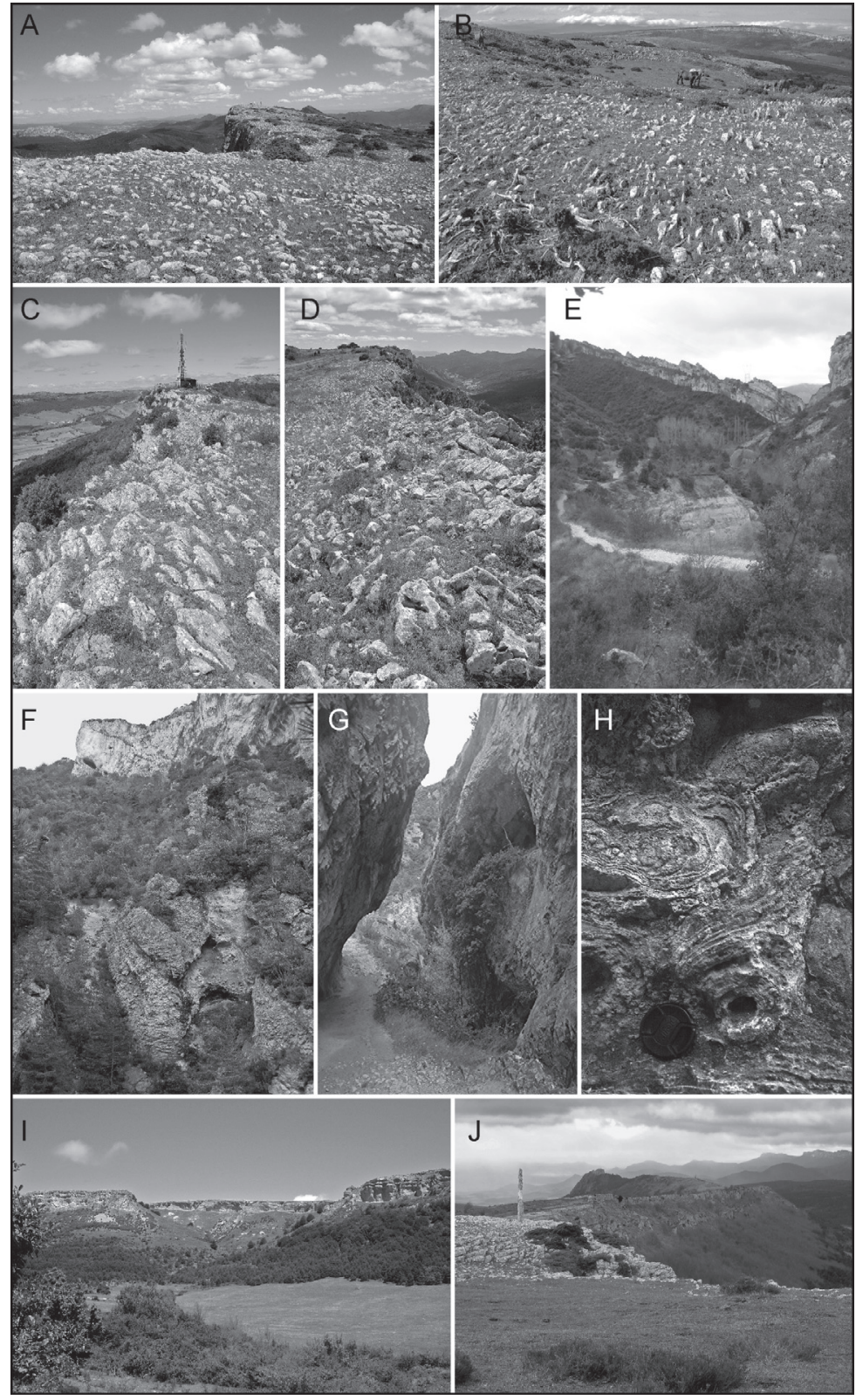

Fuente: Elaboración propia.

Una vez establecido el listado definitivo de LIGm, se procedió a la evaluación de los valores intrínsecos, añadidos y de uso y gestión en cada uno de ellos, incluyendo la información en fichas resumen. La valoración de los LIGm se ha establecido sobre un máxi- mo de 5 puntos para cada uno de los valores analizados y aparece reflejada en la Figura № 8 .

El conjunto de los LIGm propuestos presentan una alta valoración intrínseca, acorde 
a ese postulado que hacíamos respecto al cual, en los rasgos geomorfológicos radica una parte importante del atractivo de los espacios naturales y concretamente de Valderejo. Todos los LIGm son altamente representativos de formas geomorfológicas, glacis, taludes de derrubios, terrazas fluviales y fundamentalmente formas kársticas, con numerosos campos de dolinas, distintos tipos de lapiaces, o gargantas, sin embargo destacan las formas y depósitos alojados en el valle del río Purón ( $\mathrm{N}^{\circ} 3$ y $\mathrm{N}^{\circ} 4$ ) puesto que además de constituir un magnífico ejemplo de morfología fluvio-kárstica, incluyen en su interior depósitos tobáceos de alto valor paleoambiental.

El conjunto de los LIGm presentan altos valores añadidos (Figura $N^{0} 8$ ), superiores o próximos a 3, cuestión que se relaciona con la alta calidad paisajística y estética, rasgo común al conjunto de los 5 LIGm. Por otro lado, los elementos culturales, algunos de alto valor patrimonial como los restos megalíticos, las ermitas, y los vinculados a ser lugar de paso entre la cuenca alta del Ebro y la costa cantábrica, son acordes, junto a los geomorfológicos, con la propuesta de crear un parque arqueológico. De todos modos son los LIGm vinculados al valle del río Purón los que alcanzan un mayor valor, hecho relacionado sin duda con el alto valor pedagógico y didáctico de las tobas, en las que también hay que destacar la importante potencialidad científica para la reconstrucción de las condiciones hidrodinámicas pasadas y de la evolución paleoambiental, (González Amuchastegui \& Serrano, 2007, 2013).

Las principales diferencias en la valoración de los distintos geomorfositios se encuentran en los valores de uso y gestión; podemos establecer una diferencia nuevamente entre los geomorfositios 3 y 4 (fondo del valle de Purón), y los geomorfositios 1 y 2 (crestas monoclinales) y geomorfositio 5 (cierre periclinal de la combe). En el río Purón (LIGm 3 y 4) la mayor accesibilidad, alta frecuentación y la fragilidad propia de los edificios tobáceos implican vulnerabilidad y alto riesgo de degradación. Por el contrario, los geomorfositios 1, 2 y 5 tienen una vulnerabilidad muy inferior, vinculada en gran medida a su escasa accesibilidad así como a una menor fragilidad intrínseca de las propias formas y depósitos geomorfológicos alojados en cada uno de ellos.

La vulnerabilidad y riesgo de degradación combinados con la potencialidad de uso se encuentran en la base de la elaboración de las propuestas de uso y gestión para cada uno de los LIGms. En este sentido, nuevamente una mayor valoración de los valores intrínsecos y añadidos, así como un buen estado de conservación y accesibilidad de los geomorfositios $\mathrm{N}^{\circ} 3$ y $\mathrm{N}^{\circ} 4$, indica un mayor atractivo o capacidad de uso y más valor del recurso. Sin embargo es aquí donde combinando los valores de ambas entradas, hay que ser especialmente cauto a la hora de establecer propuestas de uso y gestión, si se pretende garantizar la pervivencia y buen uso del recurso. En este sentido se propone el desarrollo de figuras de especial protección que se inserten dentro de la zonificación del parque y que podrían equipararse a condicionantes superpuestos que no prohíban el uso de los geomorfositios, pero sí establezcan una forma de uso que garantice su pervivencia.

En cuanto a la orientación de uso y gestión se plantean una serie de propuestas que combinan es sus objetivos la conservación y el aprovechamiento del recurso acorde siempre con la valoración alcanzada por cada ítem en cada uno de los LIGm. Nuevamente y de manera sintética pueden agruparse los LIGm de Vallegrull, Arrayuelas y RecuencoPortillo-Lerón ( $\mathrm{N}^{\circ} 1, \mathrm{~N}^{\circ} 2$ y $\mathrm{N}^{\circ}$ 5) en los que destacan valores intrínsecos altos, por su alta representatividad y elevado valor didáctico. Sin embargo los tres presentan una potencialidad de uso media, vinculada esencialmente a su baja accesibilidad, de ahí que las propuestas de gestión se centren en una mejora de esta, mediante medidas blandas de mejora de senderos y su señalización, así como una mejora de material interpretativo tanto en el LIGm, como en los lugares más frecuentados (casa del parque, puntos de acceso al Parque), que incluya una cartografía geomorfológica, y una descripción de sus valores.

Por otro lado, los LIGm vinculados al valle del río Purón ( $\mathrm{N}^{\circ} 3$ y $\left.\mathrm{N}^{\circ} 4\right)$, presentan una alta vulnerabilidad debido a su fácil accesibilidad, la alta afluencia de visitantes y su fragilidad intrínseca, por lo que un incremento en la actual intensidad de uso, puede afectar 
Figura $\mathrm{N}^{0} 7$

Mapa geomorfológico del LIGm n 1 . Vallegrull

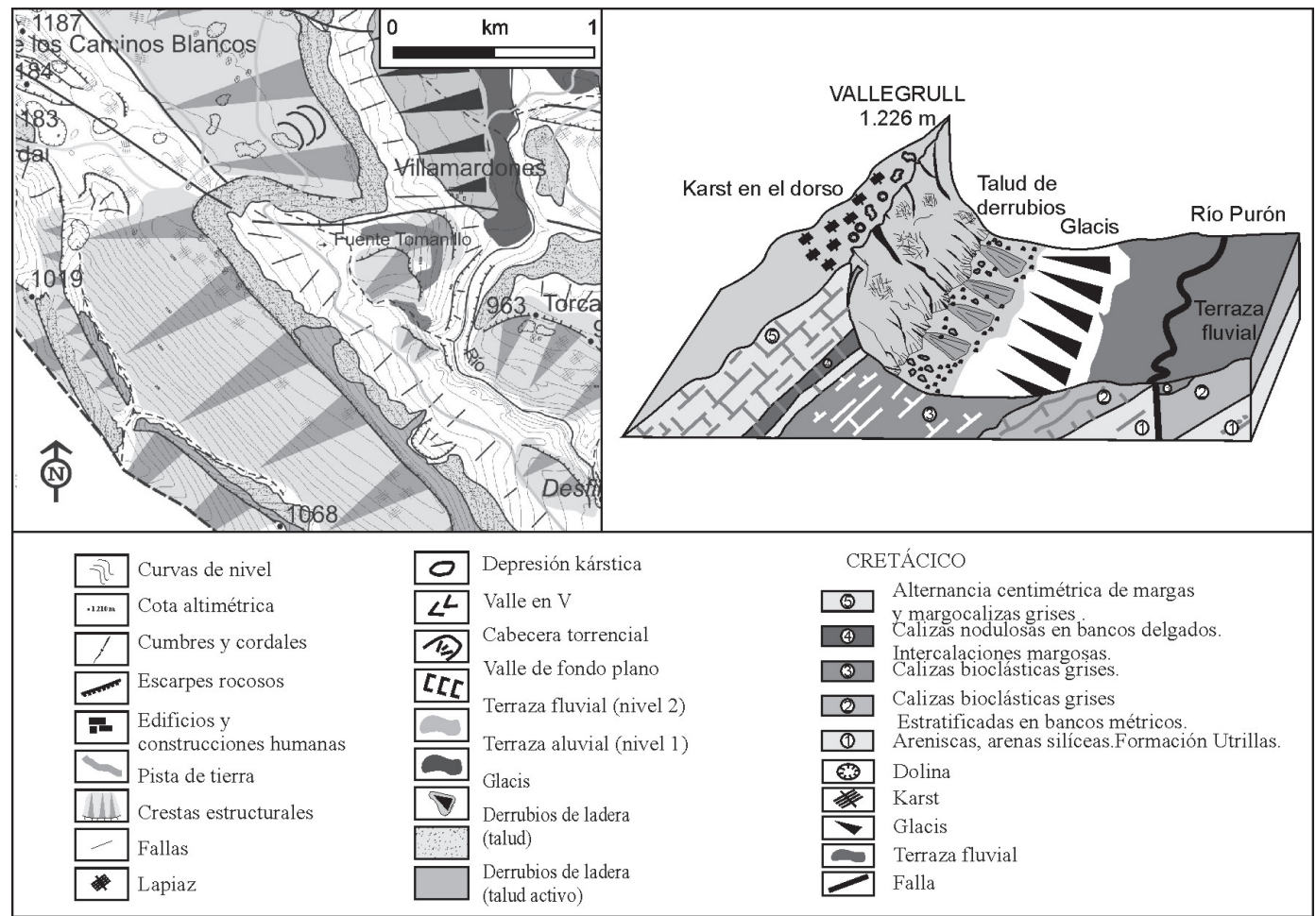

Fuente: Elaboración propia.

a sus valores. Estos LIGm requieren de un control y seguimiento de su estado de conservación de ahí que se proponga el desarrollo de una zonificación específica; esta va desde la protección estricta en algunos tramos hasta zonas que deben quedar englobadas bajo el condicionante superpuesto de limitación de uso que incluya el control de afluencia de visitantes, la elaboración de un plan específico que contenga el diseño y mejora de la red de senderos, evitando los puntos más frágiles próximos a las formaciones tobáceas ya que en algunos puntos la cercanía a estas de los caminos afectan su estado natural, viéndose alterados con facilidad debido a su alta fragilidad. Por otro lado, estos LIGm presentan un alto interés científico en lo referente a la dinámica geomorfológica fluvio-kártica: la formación por incisión fluvial de la garganta y la formación de sedimentos tobáceos, por lo que la incorporación y mejora de material interpretativo sería muy útil para la comprensión del paisaje.
Finalmente se aconseja para el conjunto de los LIGms definidos llevar a cabo el control y seguimiento de su estado de conservación, de manera que sirva para evaluar el éxito de las propuestas realizadas.

\section{Los lugares de interés geomorfológico y la gestión territorial}

En la actualidad es necesario incorporar los aspectos geomorfológicos a la gestión de los ENPs ya que constituyen elementos fundamentales en la configuración y dinámica del sistema natural y del paisaje en particular. Para ello es necesario un conocimiento exhaustivo de los elementos geomorfológicos que debe partir del estudio científico, inventariado de formas y selección de aquellas que son más relevantes; todo ello como paso previo a su valoración, promoción como recursos (culturales, didácticos, científicos, 
Figura $\mathrm{N}^{\circ} 8$

Valoración de los geomorfositios de Valderejo

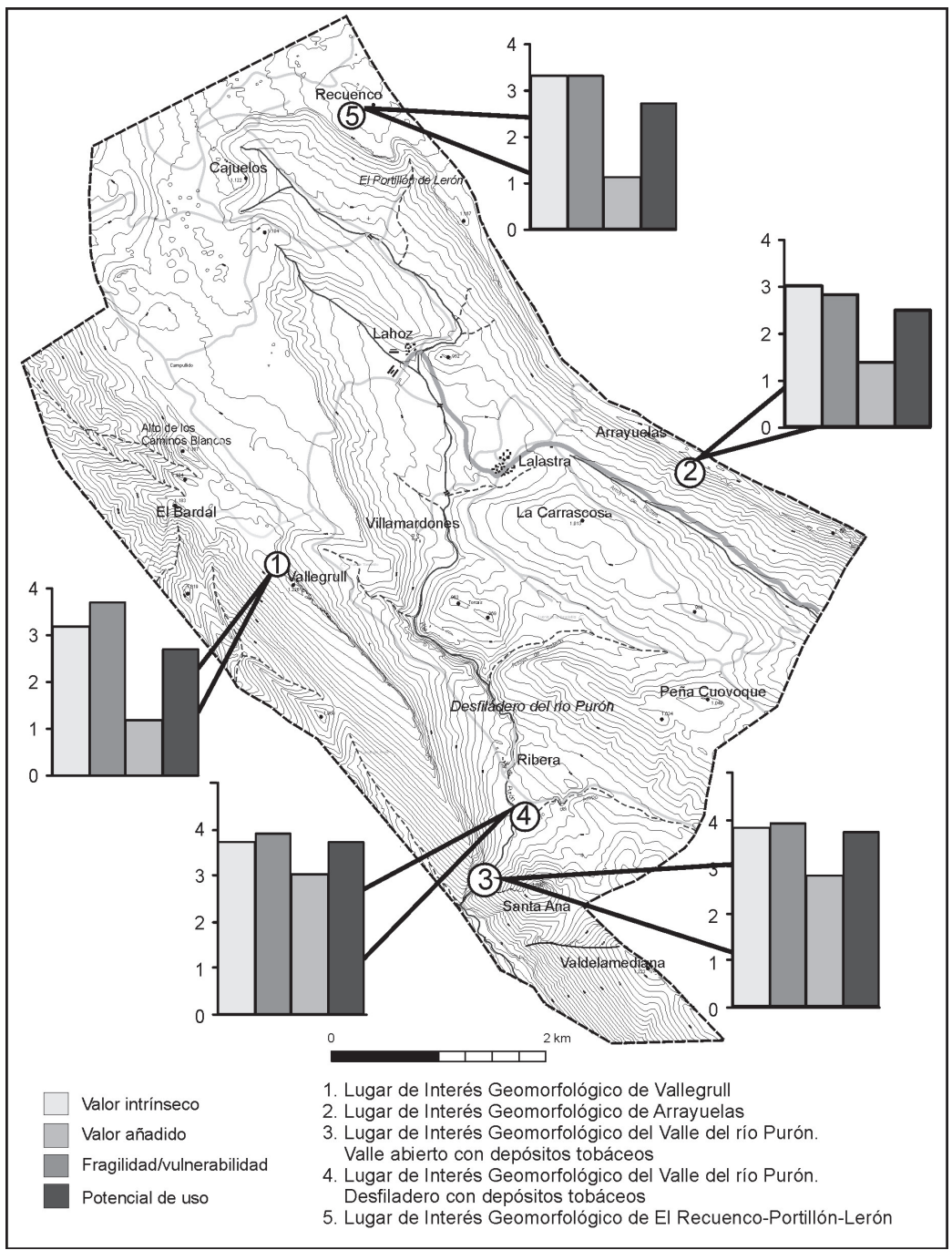

Fuente: Elaboración propia.

naturales) y elaboración de propuestas de gestión para la conservación.

La metodología empleada ha permitido definir en el Parque Natural de Valderejo un total de cinco lugares de interés geomorfológico, a partir del análisis de sus características geomorfológicas, su potencial paisajístico, cultural y de uso. El método resulta útil para ofrecer una valoración semicuantitativa global reflejada en la cartografía, y orientaciones de uso y conservación a los gestores del Parque Natural; cumple además, los objetivos requeridos en cuanto a la búsqueda de herramientas adecuadas y fácilmente utilizables por los gestores del espacio natural protegido. Con este método se consigue una mayor aplicabilidad de los geomorfositios, que de este modo pueden ser incorporados a la ordenación territorial y a la interpretación educativa y/o turística del ENP, puesto que además de su aplicación se deriva un material de fácil interpretación y uso por parte del público en general. 
Se han definido 5 lugares de interés geomorfológico, que presentan valores intrínsecos elevados, valores añadidos altos en el conjunto de ellos aunque superiores en los geomorfositios alojados en los fondos de valle. Estos últimos presentan una mayor potencialidad de uso, sin embargo su fragilidad es también elevada lo que exige medidas de protección (Figura $\mathrm{N}^{\circ} 8$ ).

La actividad turística constituye uno de los principales recursos de Valderejo e incluso algunos de los geomorfositios establecidos, nuevamente los números 3 y 4 , alojados en el fondo del valle del río Purón, podrían ser definidos como "lugares turísticos", de modo que pueden ser considerados útiles de desarrollo local. De este modo deben ser considerados recursos para cuya gestión es necesario alcanzar el equilibrio entre la conservación y el uso, para garantizar su pervivencia. Si la gestión asegura la sostenibilidad del recurso, este seguirá manteniendo todo su potencial. En este sentido, la propuesta se inserta plenamente en el modelo de gestión que persigue el Parque Natural de Valderejo, al desarrollar una de las líneas de investigación prioritarias establecidas en los criterios de gestión propuestos en el PRUG del Parque Natural (III PRUG, 2011), enmarcándose así con las políticas de gestión más innovadoras que se están aplicando en otros espacios protegidos. Sin embargo son todavía propuestas de carácter genérico, lejos de la concreción de otras vinculadas al estudio de la biodiversidad (hábitats, flora, fauna) o del patrimonio cultural.

Esta propuesta permite incorporar a la gestión territorial de los ENPs y por tanto, a su ordenación, una línea de trabajo y acción consolidada en las políticas territoriales de buena parte de los países europeos (destacan los países del arco alpino, en torno a las acciones del convenio transalpino: Suiza, Austria, Alemania, Francia, Italia), e incluso incipientemente tratada ya en algunas Comunidades Autónomas españolas.

Por otro lado, el estudio ha implicado la elaboración de una serie de documentos de información y síntesis de carácter diferenciado:

- Carácter científico. Destaca la elaboración del mapa geomorfológico y el inventario y valoración de los lugares de interés geomorfológico. Todo ello, como ya se ha expuesto más arriba, responde a un proceso de reflexión metodológica destinado a su aplicación.

- Gestión del Territorio. En todo momento ha existido una comunicación fluida con los agentes responsables de la gestión de estos espacios (Diputación Foral de Álava, Parques Naturales, Parque Natural de Valderejo). Además se ha elaborado material específico para orientar la gestión territorial adecuada y sostenible de estos espacios desde el punto de vista de la geodiversidad. En este sentido, volver a señalar que los lugares de interés geomorfológico constituyen herramientas de gestión cuya valoración debe hacerse desde una visión global e integradora que incluya sus aspectos científicos, culturales y socioeconómicos empleando una metodología que pueda ser fácilmente comprensible en distintos niveles: científico, gestión del territorio y por el público en general.

La visión integradora de la metodología aplicada que exige además de un exhaustivo análisis territorial y geomorfológico, la integración de todo un conjunto de aspectos que incrementan el valor de los geomorfositios así como el análisis de la fragilidad y potencialidad de su uso, permite definir propuestas concretas para su ordenación; estos elementos de mayor valor geomorfológico y territorial que deben ser tenidos en cuenta mediante propuestas vinculantes tanto en la zonificación de los ENPs, como en el grado de protección requerido desde la conservación estricta hasta el establecimiento de distintos condicionantes superpuestos a la ordenación de su uso.

\section{Conclusiones}

Los lugares de interés geomorfológico son formas y asociaciones de formas de relieve de especial interés monumental, escénico, ecológico, pedagógico o científico, fundamentales en la configuración morfológica de los ENPs. Su inventario, estudio y valoración resultan esenciales como instrumentos de gestión territorial.

El método empleado para la valoración de los LIGm en el Parque Natural de Valderejo se ha mostrado útil como medio para inven- 
tariar, diagnosticar y establecer propuestas encaminadas a una mejor gestión de los lugares de interés geomorfológico del Parque y ha permitido establecer una valoración comparada de los LIGm del ENP basadas en la combinación de sus valores naturales, culturales y de uso y gestión.

El exhaustivo análisis territorial y geomorfológico que requiere la metodología aplicada, permite definir propuestas concretas de ordenación de LIGm y de los ENPs.

\section{Referencias bibliográficas}

ALDAMA, A. y GALILEA, F. Investigaciones arqueológicas en Valderejo (Álava). $1^{\text {a }}$ parte: prospecciones. Estudios de Arqueología Alavesa, 2006, No 23, p. 9-68.

CENDRERO, A. El Patrimonio geológico: ideas para su protección, conservación y utilización. En: Ministerio de Medio Ambiente (MMA). El Patrimonio Geológico. Madrid: Ministerio de Medio Ambiente, 1996, p. 17-28.

DIPUTACIÓN FORAL DE ÁlAVA. III Plan Rector de Uso y Gestión del Parque Natural de Valderejo. Álava: Diputación Foral de Álava, 2011.

DÓNIZ, J.; BECERRA, R.; GONZÁLEZ, E.; GUILLÉN, C. \& ESCOBAR, E. Geomorphosites and geotourism in volcanic landscape: the example of La Corona del Lajial cinder cones (El Hierro, Canary Islands, Spain). Geolournal of Tourism and Geosites, 2011, Vol. 8, № 2, p. 185-197.

DÓNIZ, J.; DE JESÚS, J.; ZAMORANO, J. y BECERRA, R. El patrimonio geomorfológico de los volcanes de El Malpaís de Güímar (Tenerife, España) y Parícutin (Michoacán, México): implicaciones geoturísticas. Patrimonio geológico, un recurso para el desarrollo. Cuadernos del Museo Geominero, 2013, N ${ }^{\circ}$ 15 , p. 39-48.

GARAYO, J.M. La declaración de parque natural como intento de revitalización de la sociedad rural de montaña: el caso del valle de Valderejo. Zainak, 1977, Nº 14, p. 339-366.

GONZÁlEZ AMUCHASTEGUI, M.J. El desfiladero del río Purón. En: INGEBA. EI itinerario como recurso didáctico para el estudio del medio natural en Euskal Herria. Madrid: Ingeba, 1993, p. 235-248.

GONZÁLEZ AMUCHASTEGUI, M.J. y SERRANO, E. Cartografía geomorfológica del valle de Tobalina (Burgos). Cuadernos do Laboratorio Xeoloxico de Laxe, 1996, № 21, p. 737-748.

GONZÁLEZ AMUCHASTEGUI, M.J. \& SERRANO, E. Quaternary tufa buildup stages in Mediterranean-Cantabric transitional environment (High Ebro Basin, Nothern Spain). Zaragoza: International Conference on Geomorphology, 2005.

GONZÁLEZ AMUCHASTEGUI, M.J. y SERRANO, E. Evolución geomorfológica, cambios ambientales e intervención humana durante el Holoceno en la cuenca Alta del Ebro: las tobas de los valles del Purón y Molinar. Estudios Geográficos, 2007, LXVIII, No 263, p. 527-546.

GONZÁLEZ AMUCHASTEGUI, M.J. \& SERRANO, E. Holocene tufa changes as response to human impact on environment (High Ebro Basin. Northern Spain). París: International Conference on Geomorphology, 2013.

GONZÁLEZ TRUEBA, J.J. y SERRANO, E. La valoración del patrimonio geomorfológico en Espacios Naturales Protegidos. Su aplicación al Parque Nacional de los Picos de Europa. Boletín de la A.G.E., 2008, No 47, p. 175-194.

GRAY, M. Geodiversity. Valuing and conserving abiotic nature. Chichester: John Wiley \& Sons, 2004.

PANIZZA, M. Geomorphosites: concepts, methods and examples of geomorphological survey. Chinese Sciencie Bulletin, 2001, N ${ }^{\circ}$ 46 , p. $4-6$

PANIZZA, M. \& PIACENTE, S. Geomorphological assets evaluation. Zeitschrift für Geomorphologie N.F., 1993, № 87, p. 13-18.

PANIZZA, M. \& PIACENTE, S. Geomorfologia culturale. Bologna: Pitagora Ed., 2003.

PELLITERO, R.; GONZÁLEZ AMUCHASTEGUI, M.J.; RUIZ FLAÑO, P. \& SERRANO, 
E. Geodiversity and geomorphosite assesment applied to a natural protected area: the Ebro and Rudron Gorges Natural Park (Spain). Geoheritage, 2010, Vol. 3, № 3, p. 163-174.

REGOLINI, G. Cartographier les géomorphosites. Objectifs, publics et propositions méthodologiques. Lausanne : Tesis doctoral, Faculté des géosciences et de I'environnement, Université de Lausanne, 2011.

REYNARD, E. Géomorphosites et paysages. Geomorphologie. Relief, processus, environnement, 2005, No 3, p. 181-188.

REYNARD, E. Geomorphosites and landscapes. In: REYNARD E.; CORATZA P. \& REGOLINI-BISSIG G. (editors). Geomorphosites, 2009, s/n, p. 21-34.

SERRANO, E. \& GONZÁLEZ TRUEBA, J.J. Assessment of geomorphosites in natural protected areas: the Picos de Europa National Park (Spain). Geomorphologie, 2005, № 3, p. 197-208.
SERRANO, E. \& RUIZ FLAÑO, P. Geodiversity. A theoretical and applied concept. Geographica Helvetica. Swiss Journal of Geography, 2007, Vol. 3, № 62, p. 140-147.

SERRANO, E. \& RUIZ, P. Geomorphosites and Geodiversity. In: REYNARD E.; CORATZA P. \& REGOLINI-BISSIG, G. (editors). Geomorphosites, 2009, s/n, p. 51-63.

SERRANO, E.; GONZÁLEZ AMUCHASTEGUI, M.J. y RUIZ FLAÑO, P. Gestión ambiental y geomorfología: valoración de los lugares de interés geomorfológico del parque natural de las hoces del alto Ebro y Rudrón. Cuaternario \& Geomorfología, 2009, Vol. 3, № 23, p.65-82.

SERRANO, E. \& GONZÁLEZ TRUEBA, J.J. Environmental education and landscape leisure. Geotouristic map and geomorphosites in the Picos de Europa National Park. Geojournal of Tourism and Geosites, 2011, Vol. 2, No 8, p. 309-318. 